\title{
EphA2 protein expression in metastatic renal cell carcinoma treated with VEGF-inhibitors may be associated with patient survival
}

\author{
Christine Eckey ${ }^{1}$, Mathias Gugger ${ }^{2}$, Uyen Huynh-Do ${ }^{1}$ \\ 1. Division of Nephrology and Hypertension, and Department of Clinical Research, Inselspital, University of Bern Medical \\ School, Bern, Switzerland. 2. Institute of Pathology, University of Bern, Bern, Switzerland
}

Correspondence: Uyen Huynh-Do. Address: Division of Nephrology and Hypertension and Department of Clinical Research, University of Bern Medical School, Inselspital, Freiburgstrasse, CH - 3010 Bern, Switzerland.

E-mail: uyen.huynh-do@insel.ch

Received: January 12, 2013

Accepted: March 20, 2013

Online Published: March 26, 2013

DOI : $10.5430 /$ jst.v3n3p12

URL: http://dx.doi.org/10.5430/jst.v3n3p12

\section{Abstract}

Background: EphA2 is a receptor tyrosine kinase of the Eph family, which regulates angiogenesis, cell growth, survival and migration. EphA2 targeting has been proposed as a novel therapeutic strategy for neoplasms that overexpress this protein, particularly in case of resistance to VEGF-targeted therapy. This work raised the question whether EphA2 expression would be a predictive factor in patients with metastatic renal cell carcinoma (RCC) treated with VEGF inhibitors.

Methods: We analyzed the levels of EphA2 protein expression by immunohistochemistry in specimens of 23 patients with metastatic RCC, which were postsurgically treated with Anti-VEGF-therapy. The quantification of EphA2 protein expression was performed by automated digital image analysis using the open source software ImageJ. Statistical analysis using Cox proportional hazard modeling, Bayesian information criterion (BIC) statistic and Kendall's tau ( $\tau$ ) correlation was done using the program $\mathrm{R}$.

Results: The expression of EphA2 correlated significantly with the histological grading (correlation coefficient Kendall's $\tau=0.52 ; p<0.05$ for grades II and III). High levels of EphA2 expression levels by the adjacent kidney tissue of RCC tumors had a positive predictive value for overall survival, suggesting a tumor suppressive effect of EphA2 expressed in the tumor surrounding tissue. We also found a negative correlation between the EphA2 expression level in the primary tumor and the matching metastasis. These findings implicate different dominating signaling pathways in the primary tumor and its metastasis, with consequently a need for a complex therapeutic approach.

Conclusions: Our study suggests an association between EphA2 receptor expression and RCC carcinogenesis and metastasis. The differential effects of EphA2 signaling, from a tumor suppressive to a tumor promoting role, are greatly dependent upon its precise localization: In addition to its previously described tumor promoting role in EphA2 overexpressing tumors we observed an association between high levels of EphA2 in the adjacent normal kidney tissue and survival, suggesting a tumor suppressive role. An improved understanding of the different tasks of EphA2 signaling in the primary tumors, their surrounding tissues and metastases may be of benefit for a better targeting of metastatic RCC. 


\section{Key words}

EphA2, Renal cell carcinoma, Digital image analysis, Antiangiogenic therapy

\section{I ntroduction}

The Eph (Erythropoietin producing hepatocellular carcinoma) receptor family forms the largest known subfamily of receptor tyrosine kinases (RTKs) consisting of two subtypes: EphA receptors, whose ligands are primarily glycosylphosphatidylinositol (GPI)-linked ephrin-As, and EphB receptors, which bind mainly transmembrane ligands called ephrin-Bs. Eph receptors and their ligands provide a cell communication system with diverse important roles in normal development and physiology, as well as in disease pathogenesis, especially oncogenesis ${ }^{[1]}$. EphA2, a $130-\mathrm{kDa}$ protein, which is normally expressed at sites of cell-to-cell contact in adult epithelial tissues, is related to angiogenesis and invasiveness in cancerogenesis ${ }^{[2-4]}$. Recent studies have shown an overexpression of this protein in numerous epithelial-type carcinomas ${ }^{[5-8]}$ with the highest expression level observed in metastatic lesions. However its signaling is complex and often it seems to be paradoxical: There is good evidence that the Eph-ephrin signaling can both inhibit and promote tumorigenicity ${ }^{[2,4,9,10]}$.

Metastasized renal cell carcinomas (RCC) are treated with VEGF-targeted therapy since several years with greatly increased prognosis. Despite these advancements in therapy the primary and secondary resistances to anti-angiogenic treatment are major problems that could not be overcome to date, and molecular predictive factors that identify responders from non-responders remain to be identified ${ }^{[11]}$. EphA2/ephrin-A1 and VEGF signaling modulate theexpression/ activation of each other ${ }^{[2,4,12]}$, and additionally EphA2 signaling is one supposed mechanism, which contributes to resistance to VEGF-Inhibitors ${ }^{[1,13]}$. These reported associations between EphA2 signaling and the VEGF pathway strongly suggest an influence of EphA2 protein expression on response to VEGF-targeted therapy.

So far there has been only one report regarding EphA2 protein expression in renal cell carcinoma (RCC). The authors found a correlation between EphA2 overexpression and more highly vascularized tumors, and EphA2 overexpression was a negative prognostic marker for disease-free and overall survival after surgical resection ${ }^{[14]}$. Our work focuses on the question whether EphA2 expression in metastatic RCC is a predictive factor for response to VEGF targeted therapy. The aim of this pilot study was therefore to quantify the EphA2 protein expression of primary and metastatic RCC and to determine the relationship between expression level and clinicopathologic data.

\section{Materials and methods}

\subsection{Patients and tissues}

We analyzed the levels of EphA2 protein expression in RCC tumors and adjacent normal kidney specimens by immunohistochemistry in a total of 23 patients ( 8 females and 15 males, average age $=59$ years; range $=26-79$ years old at the start of therapy). All patients suffered from metastatic RCC and were postsurgically treated with anti-VEGF-therapy. Primary tumor samples were taken from nephrectomy preparations, and the analyzed metastases were excised before initiation of anti-VEGF-therapy. Of the 23 RCC tumors evaluated, 22 were diagnosed as conventional clear cell RCC and one as papillary RCC. Cases of Renal Cell Carcinoma with start of Anti-VEGF-Therapy (Nexavar, Sutent) between November 2006 and March 2011 were retrieved from the Institute of Oncology of the University Bern. The follow-up time was at least one year. Clinicopathologic data and paraffin-embedded materials were collected from the Institute of Pathology of the University Bern. According to the national and local ethical guidelines (University of Bern, University Hospital of Bern), patients were asked to give written informed consent for utilization of their biopsies and data for research purposes only and in a manner warranting strict confidentiality. 


\subsection{I mmunohistochemistry}

For immunohistochemical labeling we used a protocol with an affinity purified rabbit polyclonal antibody to EphA2 (1:1000 dilution; Santa Cruz Biotechnology, clone C-20) and Liquid Permanent Red (Dako) as the chromogen because of its good spectral characteristics. In order to reduce intra- and interspecimen variations we stained and evaluated two serial sections from three specimens for every patient. Always one of the three specimens comprised the tumor border with adjacent normal kidney tissue. To reduce interference of the staining with Liquid Permanent Red in the digital image analysis, no counterstaining was performed. Additionally we counterstained one more section with haematoxylin to localize the positive immunohistochemical reaction with Liquid Permanent Red.

Figure 1. EphA2 immunolabeling patterns in primary renal cell carcinomas.

There are different patterns of EphA2 protein in RCCs. Picture A shows a more diffuse staining and picture $\mathbf{B}$ a more clustered pattern. These different expression patterns could be due to differing phases of cancerogenesis, in which EphA2 amplification occurs.
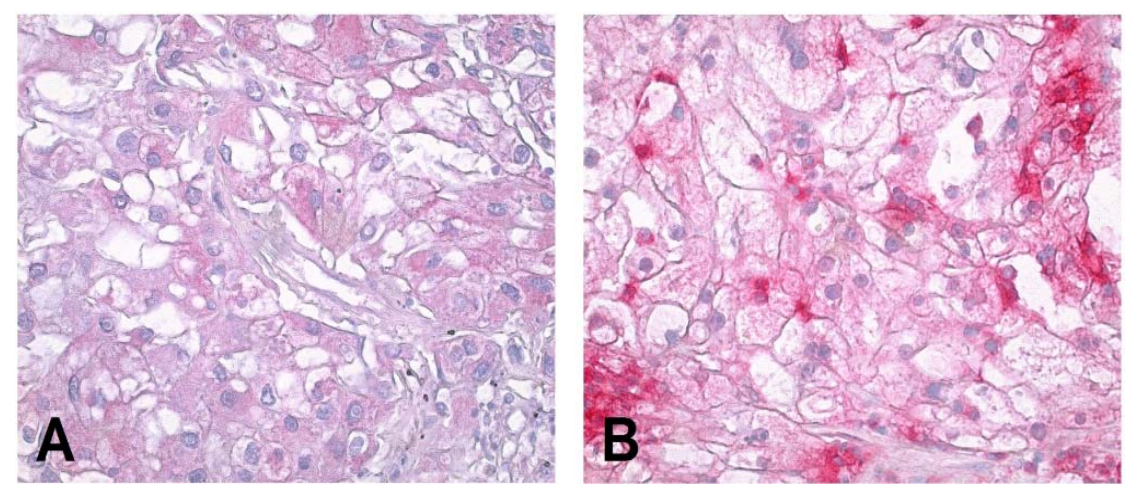

\subsection{Digital image analysis}

For quantification of EphA2 protein expression, we took 15-20 pictures of every primary tumor slide plus 12-15 of the adjacent kidney tissue under 40x magnification (Software: BR-NIS-Elements, Nikon Eclipse 800), always using the same settings. In metastases, 8-25 pictures were taken depending on the specimen's size. Afterwards automated digital image analysis was performed using the software ImageJ (National Institute of Health, Wayne Rasband). First we determined our individual color vectors (e.g. a red vector stands for Liquid Permanent Red, representing EphA2 protein expression) using single stained slices. Next we used the ImageJ plugin "Colour deconvolution" to spectrally separate our immunohistochemical stained slides in pictures with only one color. We converted the image with the Liquid Permanent Red coloring in an 8-bit greyscale and measured the integrated color density. The arithmetical middle of the aggregate determinations of EphA2 expression intensity (represented by the integrated color intensity of Liquid Permanent Red) for each tumor and matched normal adjacent kidney specimen were calculated for each patient. For metastases the analyzing algorithm was just the same.

Figure 2. The influence of EphA2 expression levels in the adjacent normal kidney tissue of RCCs on survival:

The EphA2 expression level of the adjacent normal kidney tissue has an exponentiated coefficient of 0.96 $(p<0.05)$ in the Cox regression. For illustration, COX regression curves of tertile groups of the EphA2 expression level in the adjacent normal kidney tissue are shown.

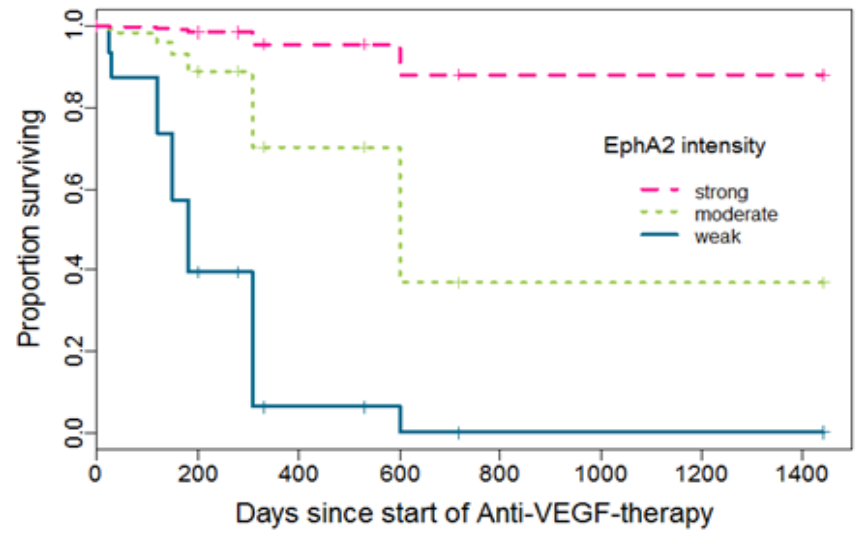




\subsection{Statistical analysis}

Statistics were done using R (The R Foundation for Statistical Computing). Correlation analyses were assessed using Kendall's tau correlation. This correlation analysis has fewer requirements to the sample cohort as other correlation coefficients, especially in question of sample sizes. $P<0.05$ was considered significant. In these analyses, two RCC subtypes were included without distinction. To investigate whether levels of EphA2 protein expression and other parameters were associated with mortality, Cox proportional hazard modeling was used, allowing working with censored data. To find the model with the highest predictability and the best fit, we used the Bayesian information criterion (BIC) statistic (package "BMA", R) ${ }^{[15-17]}$.

Table 1. Patient and Disease Characteristics $(\mathrm{N}=23)$

\begin{tabular}{|c|c|c|}
\hline \multirow{2}{*}{ Variable } & \multicolumn{2}{|c|}{ Patients } \\
\hline & No. & $\%$ \\
\hline \multicolumn{3}{|l|}{ Age at targeted therapy initiation [years] } \\
\hline Median & \multicolumn{2}{|l|}{64} \\
\hline Interquartile range & \multicolumn{2}{|c|}{$56.5-71$} \\
\hline Range & \multicolumn{2}{|c|}{$26-79$} \\
\hline \multicolumn{3}{|c|}{ Time from diagnosis to targeted therapy [years] } \\
\hline Median & \multicolumn{2}{|c|}{1.41} \\
\hline Interquartile range & \multicolumn{2}{|c|}{$0.26-4.26$} \\
\hline Range & \multicolumn{2}{|c|}{$0.03-16.82$} \\
\hline \multicolumn{3}{|l|}{ Sex } \\
\hline Male & 15 & 65 \\
\hline \multicolumn{3}{|l|}{ Histology } \\
\hline Clear cell & 22 & 96 \\
\hline Non-clear cell & 1 & 4 \\
\hline Prior nephrectomy & 18 & 78 \\
\hline \multicolumn{3}{|l|}{ Grade (in nephrectomy samples) } \\
\hline I & 1 & 6 \\
\hline II & 6 & 33 \\
\hline III & 8 & 44 \\
\hline IV & 3 & 17 \\
\hline \multicolumn{3}{|l|}{ No. of metastases } \\
\hline 1 & 6 & 26 \\
\hline$>1$ & 17 & 74 \\
\hline Liver metastases present & 7 & 30 \\
\hline Brain metastases present & 4 & 17 \\
\hline Sunitinib induced hypertension present & 0 & 0 \\
\hline Dose reduction of targeted therapy & 8 & 35 \\
\hline
\end{tabular}

\section{Results}

Patient baseline characteristics are presented in Table 1. All patients were treated with sunitinib or sorafenib, but eight patients (35\%) needed dose reduction because of adverse effects. Eighteen patients (78\%) had prior nephrectomy. The 
median time on initial VEGF-targeted therapy was 5.2 months, the median follow-up time after treatment initiation was 26.6 months and the median OS of all patients was 34.8 months.

\subsection{EphA2 expression in RCC}

All RCC tumors expressed EphA2, wherein two different patterns of staining were observed: EphA2 "clusters" (about $25 \%$ ) as well as a more diffuse expression (75\%) throughout the tumorous tissue (Figure $1 \mathrm{~A}$ and $\mathrm{B}$ ). The clustered pattern suggests an EphA2 amplification as a later event in carcinogenesis, whereas the diffuse pattern was compatible with an earlier process. Furthermore, almost $90 \%$ of the RCC overexpressed EphA2 compared with the adjacent normal kidney tissue. The expression of EphA2 correlated significantly with the histological grading (correlation coefficient Kendall's $\tau=0.52 ; p<0.05$ for grades II and III), which is consistent with a report from Herrem et al. ${ }^{[14]}$ demonstrating similar associations.

\subsection{High levels of EphA2 expression levels in the adjacent normal kidney tissue of RCC tumors have a positive association with overall survival}

In the following we examined the impact of EphA2 protein expression levels on the clinical response to anti-VEGF, using the BIC test on survival data (results are displayed in Table 2). For comparability and completeness we incorporated only the data of patients who had a nephrectomy $(\mathrm{N}=18)$. We examined all factors named in Table 1 except the histology and Sunitinib induced hypertension because of the absence of differences. The highest contribution to the assignment to high or low surviving probability came from the level of EphA2 protein expression in the adjacent normal kidney tissue. This EphA2 expression level had an exponentiated coefficient of $0.97(p<0.05)$, implicating that a higher expression level of EphA2 is associated with increased probability of survival. To illustrate this relationship, we divided our cohort into tertile groups, according to the height of their EphA2 expression levels in the adjacent normal kidney tissue, and generated a survival curve plot (see Figure 2). The group with the highest expression level of EphA2 in the adjacent normal kidney tissue had the best survival probability at every time $t$ compared to the other groups, while the group with the lowest expression of EphA2 in the adjacent normal kidney tumor had the worst survival probability. In aggregate, our findings highly suggest that the level of EphA2 protein expression in the adjacent normal kidney tissue of renal cell carcinomas is predictive for overall survival after the start of anti-VEGF-therapy.

Table 2. Posterior parameter estimates (means), standard deviations and probabilities (pr) [\%] that the coefficients ( $\theta$ ) are non-zero for the variables *

\begin{tabular}{llll}
\hline Variable & Mean & Standard deviation & pr $(\boldsymbol{\theta} \neq \mathbf{0})$ \\
\hline Sex & 0.1063 & 2.7571 & 25.5 \\
Age & 0.0656 & 0.3354 & 37.8 \\
Dose reduction of targeted therapy & 0.2551 & 1.1519 & 26.1 \\
Time from diagnosis to treatment & -0.0022 & 0.0018 & 99.7 \\
Metastatic sites & 0.3131 & 7.3990 & 28.7 \\
Liver metastasis & -1.7580 & 8.0296 & 45.6 \\
Brain metastasis & 0.2051 & 2.8494 & 29.3 \\
Grade & -0.1281 & 0.6888 & 21.7 \\
EphA2 protein expression & & & \\
in the primary tumor & 0.2507 & 1.5800 & 30.4 \\
in the adjacent normal kidney tissue & -0.0374 & 0.0311 & 95.0 \\
\hline
\end{tabular}

${ }^{*}$ Means and standard deviations are averaged over all models included in the BMA analysis.

Bayesian model averaging results: The probabilities that the coefficient is not zero $(\operatorname{pr}(\theta \neq 0))$ are only for the variables "Time from diagnosis to treatment" $(\mathrm{pr}=99,7 \%)$ and "EphA2 protein expression in the adjacent normal kidney tissue" (pr=95\%) higher than $75 \%$, which can be interpreted as "positive evidence" [17]. The best fitting model for prediction of survival calculated by the test model averaging involves these both variables. 


\subsection{Negative correlation between the EphA2 expression level in the primary tumor and the matching metastasis}

As demonstrated in Figure 3, there was a variable relationship between the expression levels of EphA2 in the primary tumor and its matching metastasis. Comparison of the EphA2 expression level of the primary tumor versus the matching metastasis clearly demonstrated a negative correlation: The higher the EphA2 expression level of the primary tumor, the lower its expression in the matching metastasis. We found this negative correlation between the EphA2 expression level in the primary tumor and the matching metastasis to be highly significant $(p<0.0018$, correlation coefficient Kenndall's tau-0.86) (Figure 4).

Figure 3. Two examples for opposed expression of EphA2 in a primary tumor and its matching metastasis:

Picture A shows a tumor with very low expression of EphA2 and $\mathbf{B}$ the matching metastasis with high expression of EphA2 whereas picture $\mathbf{C}$ shows a primary tumor with high expression of EphA2 and the matching metastasis in $\mathbf{D}$ shows nearly no expression.

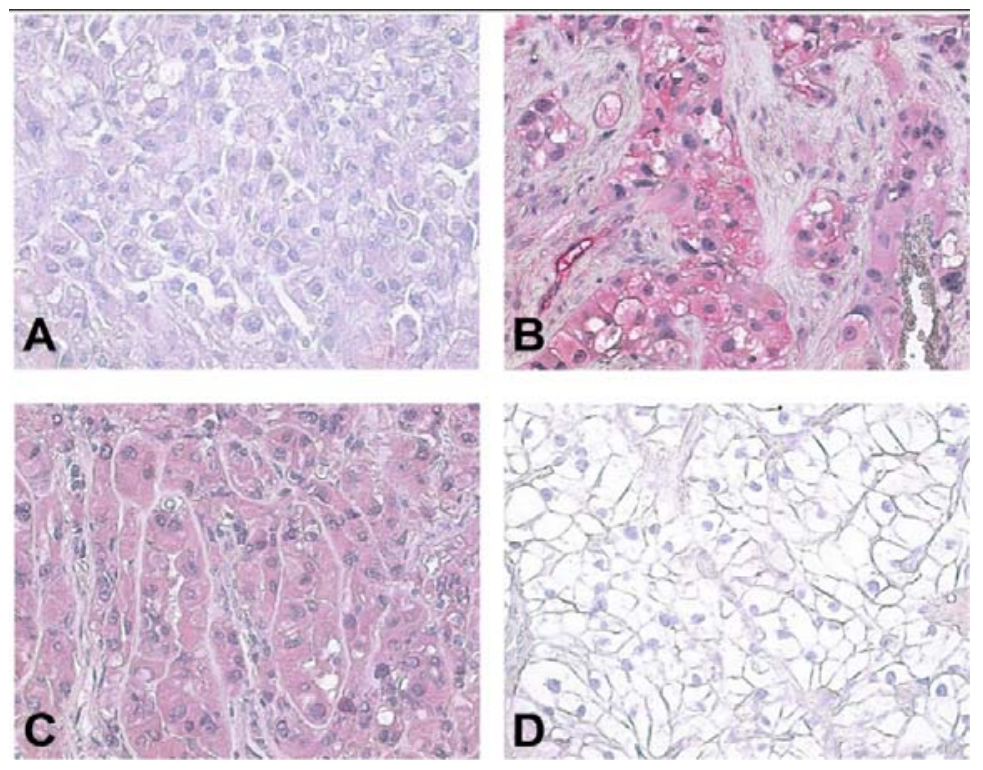

Figure 4. Correlation analysis of EphA2 expression in primary tumors and their metastases:

On the $\mathrm{x}$-axis EphA2 protein expression levels in the primary tumor are plotted and on the y-axis EphA2 protein expression levels of their matching metastasis. Expression levels are represented by integrated color intensities (ICI) measured with automated digital image analysis. The EphA2 expression level of metastases correlates negative with the EphA2 expression level in the matching primary tumor. The correlation coefficient (Kenndall's tau) of the ICIs respectively is $-0.86(p<0.0018)$.

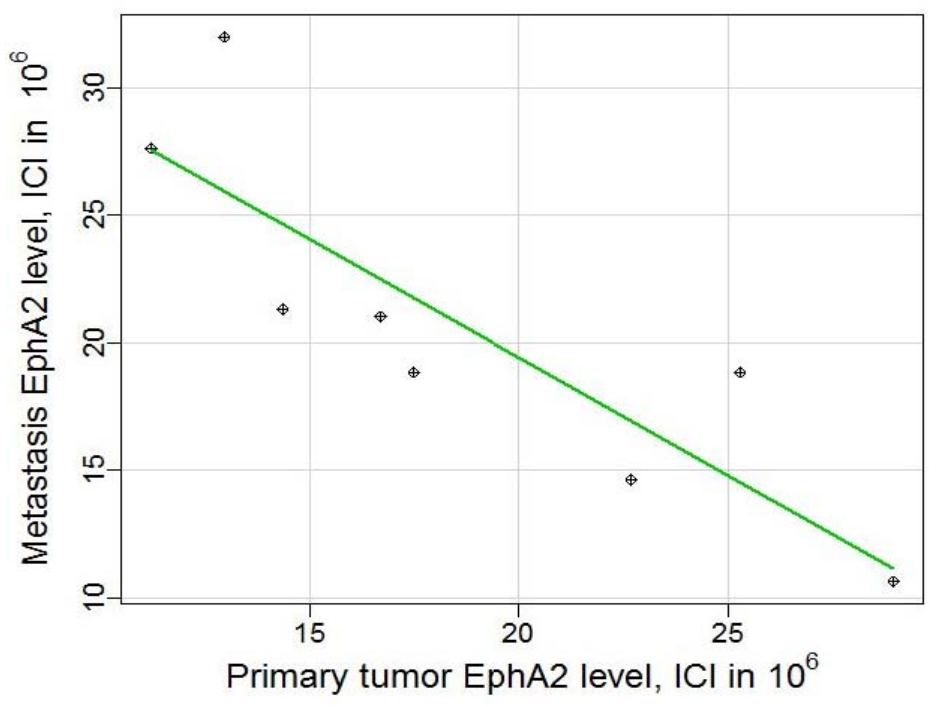




\section{Discussion}

Because many patients with RCC are asymptomatic at the beginning of the course of disease, the tumor stage is often advanced at diagnosis. Therefore roughly 25 percent of patients either have an advanced locoregional disease or distant metastases (Stage IV disease) at presentation. In stage IV diseases the median survival has never risen above 27 months, and the five-year survival rate is less than 10 percent ${ }^{[18]}$. The improved understanding of RCC pathogenesis has struck a new path in therapeutic options. In particular, the identification of pro-angiogenic pathways as a relevant therapeutic target has revolutionized the therapy of advanced RCC in the last decade ${ }^{[11,19]}$. Despite great advancements in therapy several issues remain to be addressed. The primary and secondary resistances to treatment are major problems that could not be overcome to date, and molecular predictive factors that distinguish responders from non-responders remain to be identified.

Recent publications refer to the management of anti-angiogenic therapy and focus on the mechanisms of resistance in particular ${ }^{[1,13]}$. EphA2/ephrin-A1 signaling is one supposed pathway, which contributes to resistance to VEGF-Inhibitors, and mutual modulating activities on expression/activation were observed ${ }^{[2,4,12]}$. In spite of these new findings the precise mechanisms underlying the interplay of VEGF and EphA2 signaling are still to be uncovered.

Besides its impact on tumor angiogenesis EphA2-overexpression in tumor cells can cause disruption of cell-to-cell contacts and an enhancement of cell-to-extracellular matrix attachments. These invasive properties and increased motility abilities result consequently in a pro-metastatic phenotype ${ }^{[14,20-22]}$. According to the complex and varying signaling functions of EphA2 in tumorigenesis, different modulation systems for Eph signaling were reported, e.g. modulation through the quantity of available ligand ${ }^{[23]}$, receptor dephosphorylation or degradation ${ }^{[24,25]}$, as well as downstream signaling pathway regulation, but the precise mechanisms leading to tumor promotion or inhibition remain to be defined.

EphA2 targeting has been proposed as a novel therapeutic strategy for neoplasms that overexpress this protein ${ }^{[3,26,27]}$. Nevertheless, there is to date no resounding Eph-targeting drug found due to unexpected impacts in therapy through heterogeneous effects of Eph-ephrin signaling in tumors ${ }^{[4]}$. Improved understanding and further investigations are needed to use the Eph-ephrin signaling system in the clinical treatment of human cancer.

Two important novel conclusions can be drawn from our study. First we demonstrated that the EphA2 expression level in the normal adjacent kidney tissue in RCC may have an impact on response to anti-VEGF-therapy. High levels of EphA2 in the normal adjacent kidney tissue seemed to have a positive influence on the clinical response to anti-VEGF-therapy and ultimately on overall survival. In some murine tumor models, a tumor suppressor effect of Eph forward signaling in the tumor surrounding tissue could also be shown ${ }^{[28,29]}$. In these studies Eph-ephrin interactions have been proposed to inhibit expansion and invasiveness of incipient colorectal and skin tumors. Additionally anti-angiogenic agents can enhance the development of vessel abnormalities, which results in increased hypoxia and a pro-tumorigenic inflammatory state ${ }^{[1,30]}$. The pro-angiogenic Eph-ephrin signaling complex could reduce the negative effect of anti-angiogenic drugs on vessels. In addition a better drug delivery into the tumor tissue through the pro-angiogenic effects of the Eph-ephrin system in the tumor surrounding tissue could act synergistically with anti-VEGF treatments.

Second, our finding of a negative correlation between EphA2 protein expression levels in primary tumors when compared to their matching metastases could have a great importance with regard to EphA2-targeting drugs. Mudali et al. ${ }^{[31]}$ also mentioned in their study different EphA2 levels in primary tumors and their matching metastasis. These unequal expression levels indicate different dominating signaling pathways in primary tumors and metastases. In previous studies significant interactions between EphA2/ephrin-A1 signaling and cadherins, in particular E-cadherin, were observed ${ }^{[20,32]}$. For example the cellular location of EphA2 in E-cadherin-negative tumors is changed from cell-cell contact sites to membrane ruffles, which leads to increased motility and invasive properties ${ }^{[9,32]}$. Even expression levels of EphA2 are modulated by cadherins. This relationship is one of various described mechanisms belonging to epithelial-to-mesenchymal transition (EMT), a process strongly associated with cancer cell invasion and metastasis, and 
the contrary process, which is assumed to occur primary in metastases, the mesenchymal-to-epithelial transition (MET) ${ }^{[4,9,33-35]}$. Corresponding to these observations, EphA2 expression levels of tumor cells could depend on their state between a more epithelial and a more mesenchymal phenotype. But whereas EphA2 signaling can influence the invasiveness and metastatic dissemination through various mechanisms ${ }^{[21-23,36-41]}$, our observations suggest that in metastases EphA2 signaling differs in function from primary tumors, rendering targeted therapy much more complex.

Indeed this pilot study did not incorporate data from a large number of patients; however evaluation with automated digital image analysis produces much more valid values for each patient than traditional manual scoring systems. This estimation is non-subjective and includes through automation a considerable greater amount of information than one could reach through manual evaluation. Nevertheless future investigations with larger powered studies are needed to further consolidate these results. A second limitation of our study is the lack of several clinical and laboratory variables described by Heng et al. ${ }^{[42]}$ as additional prognostic factors. Due to the retrospective study design the dataset contained missing values preventing the calculation of the HENG/memorial risk score. As our study is intended to make a contribution to comprehension of tumor biology of RCC more than generating a new clinical predictive model we had to accept this limitation when designing this study. Finally we would like to mention the fact that no comparable control group was available, because VEGF-targeted therapy is only accredited for metastatic RCC (new guidelines mention this therapy option for locally advanced RCCs only in experimental approaches ${ }^{[43]}$ ).

\section{Conclusion}

Our pilot study suggests important and versatile roles of EphA2 receptor in RCC carcinogenesis and metastasis. The expression patterns of EphA2 in RCC are heterogeneous, and the differential effects of EphA2 signaling, from a tumor suppressive to a tumor promoting role, seem to be greatly dependent upon its precise localization. An improved understanding of the different roles of EphA2 signaling in the primary tumors, their surrounding tissues and metastases may be of benefit for a better targeting of metastatic RCC.

\section{Acknowledgements}

We would like to thank Prof. A. Ochsenbein, Division of Oncology, University Hospital Bern, for helping us with access to the clinical data. This work has been supported by grant Nr. 3100A0-1183691 of the Swiss National Foundation to UH.

\section{Authors' contributions}

C. Eckey performed and interpreted the experiments, and wrote the article. M. Gugger helped in the selection of the patients and the design of the study, U. Huynh-Do designed the study, interpreted the results and wrote the article.

\section{Conflicting interests}

The authors declare that they have no conflict of interest.

\section{References}

[1] S. Tugues, S. Koch, L. Gualandi, X. Li, L. Claesson-Welsh. Vascular endothelial growth factors and receptors. Mol Aspects Med. 2011. PMid:21565214 http://dx.doi.org/10.1016/j.mam.2011.04.004

[2] A. Beauchamp, W. Debinski. Ephs and ephrins in cancer: ephrin-A1 signalling. Semin. Cell Dev. Biol. 2012; 23: 109-115. PMid:22040911 http://dx.doi.org/10.1016/j.semcdb.2011.10.019

[3] M. Tandon, S. V. Vemula, S. K. Mittal. Emerging strategies for EphA2 receptor targeting for cancer therapeutics. Expert Opin. Ther. Targets. 2011; 15: 31-51. PMid:21142802 http://dx.doi.org/10.1517/14728222.2011.538682

[4] E. B. Pasquale. Eph receptors and ephrins in cancer. Nat Rev Cancer. 2010; 10: 165-180. PMid:20179713 http://dx.doi.org/10.1038/nrc2806 
[5] S. Yachida, C. A. Iacobuzio-Donahue. The pathology and genetics of metastatic pancreatic cancer. Arch. Pathol. Lab. Med. 2009; 133: 413-422. PMid:19260747

[6] J. M. Brannan, B. Sen, B. Saigal, L. Prudkin, C. Behrens, L. Solis et al. EphA2 in the early pathogenesis and progression of non-small cell lung cancer. Cancer Prev Res (Phila). 2009; 2: 1039-1049. PMid:19934338 http://dx.doi.org/10.1158/1940-6207.CAPR-09-0212

[7] N. I. Herath, A. W. Boyd. The role of Eph receptors and ephrin ligands in colorectal cancer. Int. J. Cancer. 2010; 126 : $2003-2011$. PMid:20039322

[8] W. M. Merritt, A. A. Kamat, J.-Y. Hwang, J. Bottsford-Miller, C. Lu, Y. G. Lin et al. Clinical and biological impact of EphA2 overexpression and angiogenesis in endometrial cancer. Cancer Biol. Ther. 2011; 10: 1306-1314. PMCid:3047089 http://dx.doi.org/10.4161/cbt.10.12.13582

[9] M. Kandouz. The Eph/Ephrin family in cancer metastasis: communication at the service of invasion. Cancer Metastasis Rev. 2012; 31: 353-373. PMid:22549394 http://dx.doi.org/10.1007/s10555-012-9352-1

[10] D. M. Brantley-Sieders. Clinical relevance of Ephs and ephrins in cancer: lessons from breast, colorectal, and lung cancer profiling. Semin. Cell Dev. Biol. 2012; 23: 102-108. PMid:22040912 http://dx.doi.org/10.1016/j.semcdb.2011.10.014

[11] B. I. Rini. New strategies in kidney cancer: therapeutic advances through understanding the molecular basis of response and resistance. Clin. Cancer Res. 2010; 16: 1348-1354. PMid:20179240 http://dx.doi.org/10.1158/1078-0432.CCR-09-2273

[12] D. M. Brantley-Sieders, W. B. Fang, Y. Hwang, D. Hicks, J. Chen. Ephrin-A1 facilitates mammary tumor metastasis through an angiogenesis-dependent mechanism mediated by EphA receptor and vascular endothelial growth factor in mice. Cancer Res. 2006; 66: 10315-10324. PMid:17079451 http://dx.doi.org/10.1158/0008-5472.CAN-06-1560

[13] S. E. Abdullah, R. Perez-Soler. Mechanisms of resistance to vascular endothelial growth factor blockade. Cancer. 2012; 118: 3455-3467. PMid:22086782 http://dx.doi.org/10.1002/cncr.26540

[14] C. J. Herrem, T. Tatsumi, K. S. Olson, K. Shirai, J. H. Finke, R. M. Bukowski et al. Expression of EphA2 is prognostic of disease-free interval and overall survival in surgically treated patients with renal cell carcinoma. Clin. Cancer Res. 2005; 11: 226-231. PMid: 15671550

[15] J. L. Januzzi, S. Rehman, T. Mueller, R. R. J. van Kimmenade, D. M. Lloyd-Jones. Importance of biomarkers for long-term mortality prediction in acutely dyspneic patients. Clin. Chem. 2010; 56: 1814-1821. PMid:20921266 http://dx.doi.org/10.1373/clinchem.2010.146506

[16] The R Foundation for Statistical Computing. R.

[17] C. T. Volinsky, D. Madigan, A. E. Raftery, R. A. Kronmal. Bayesian Model Averaging in Proportional Hazard Models: Assessing the Risk of a Stroke. J Royal Statistical Soc C. 1997; 46: 433-448. http://dx.doi.org/10.1111/1467-9876.00082

[18] E. Cho, H.-O. Adami, P. Lindblad. Epidemiology of renal cell cancer. Hematol. Oncol. Clin. North Am. 2011; 25: 651-665. PMid:21763961 http://dx.doi.org/10.1016/j.hoc.2011.04.002

[19] M. Milella, A. Felici. Biology of metastatic renal cell carcinoma. J Cancer. 2011; 2: 369-373. http://dx.doi.org/10.7150/jca.2.369

[20] N. D. Zantek, M. Azimi, M. Fedor-Chaiken, B. Wang, R. Brackenbury, M. S. Kinch. E-cadherin regulates the function of the EphA2 receptor tyrosine kinase. Cell Growth Differ. 1999; 10: 629-638. PMid:10511313

[21] W. B. Fang, R. C. Ireton, G. Zhuang, T. Takahashi, A. Reynolds, J. Chen. Overexpression of EPHA2 receptor destabilizes adherens junctions via a RhoA-dependent mechanism. J. Cell. Sci. 2008; 121: 358-368. PMid:18198190 http://dx.doi.org/10.1242/jcs.017145

[22] M. L. Taddei, M. Parri, A. Angelucci, F. Bianchini, C. Marconi, E. Giannoni et al. EphA2 induces metastatic growth regulating amoeboid motility and clonogenic potential in prostate carcinoma cells. Mol. Cancer Res. 2011; 9: 149-160. PMid:21205836 http://dx.doi.org/10.1158/1541-7786.MCR-10-0298

[23] U. Huynh-Do, E. Stein, A. A. Lane, H. Liu, D. P. Cerretti, T. O. Daniel. Surface densities of ephrin-B1 determine EphB1-coupled activation of cell attachment through alphavbeta3 and alpha5beta1 integrins. EMBO J. 1999; 18: 2165-2173. PMid:10205170 http://dx.doi.org/10.1093/emboj/18.8.2165

[24] K. Fasen, D. P. Cerretti, U. Huynh-Do. Ligand binding induces Cbl-dependent EphB1 receptor degradation through the lysosomal pathway. Traffic. 2008; 9: 251-266. PMid:18034775 http://dx.doi.org/10.1111/j.1600-0854.2007.00679.x

[25] N.-Y. Yang, C. Fernandez, M. Richter, Z. Xiao, F. Valencia, D. A. Tice et al. Crosstalk of the EphA2 receptor with a serine/threonine phosphatase suppresses the Akt-mTORC1 pathway in cancer cells. Cell. Signal. 2011; 23: $201-212$. PMid:20837138 http://dx.doi.org/10.1016/j.cellsig.2010.09.004

[26] K. Carles-Kinch, K. E. Kilpatrick, J. C. Stewart, M. S. Kinch. Antibody targeting of the EphA2 tyrosine kinase inhibits malignant cell behavior. Cancer Res. 2002; 62: 2840-2847. PMid:12019162

[27] D. Jackson, J. Gooya, S. Mao, K. Kinneer, L. Xu, M. Camara et al. A human antibody-drug conjugate targeting EphA2 inhibits tumor growth in vivo. Cancer Res. 2008; 68: 9367-9374. PMid:19010911 http://dx.doi.org/10.1158/0008-5472.CAN-08-1933 
[28] H. Guo, H. Miao, L. Gerber, J. Singh, M. F. Denning, A. C. Gilliam et al. Disruption of EphA2 receptor tyrosine kinase leads to increased susceptibility to carcinogenesis in mouse skin. Cancer Res. 2006; 66: 7050-7058. PMid:16849550 http://dx.doi.org/10.1158/0008-5472.CAN-06-0004

[29] C. Cortina, S. Palomo-Ponce, M. Iglesias, J. L. Fernández-Masip, A. Vivancos, G. Whissell et al. EphB-ephrin-B interactions suppress colorectal cancer progression by compartmentalizing tumor cells. Nat. Genet. 2007; 39: 1376-1383. PMid:17906625 http://dx.doi.org/10.1038/ng.2007.11

[30] A. E. Hansen, A. T. Kristensen, I. Law, J. T. Jørgensen, S. A. Engelholm. Hypoxia-inducible factors--regulation, role and comparative aspects in tumourigenesis. Vet Comp Oncol. 2011; 9: 16-37. PMid:21303451 http://dx.doi.org/10.1111/j.1476-5829.2010.00233.x

[31] S. V. Mudali, B. Fu, S. S. Lakkur, M. Luo, E. E. Embuscado, C. A. Iacobuzio-Donahue. Patterns of EphA2 protein expression in primary and metastatic pancreatic carcinoma and correlation with genetic status. Clin. Exp. Metastasis. 2006; 23: 357-365. PMid:17146615 http://dx.doi.org/10.1007/s10585-006-9045-7

[32] S. Orsulic, R. Kemler. Expression of Eph receptors and ephrins is differentially regulated by E-cadherin. J. Cell. Sci. 2000 ; 113 (Pt 10): 1793-1802. PMid:10769210

[33] F. van Zijl, G. Krupitza, W. Mikulits. Initial steps of metastasis: cell invasion and endothelial transmigration. Mutat. Res. 2011; 728: 23-34. PMid:21605699 http://dx.doi.org/10.1016/j.mrrev.2011.05.002

[34] M. Guarino, B. Rubino, G. Ballabio. The role of epithelial-mesenchymal transition in cancer pathology. Pathology. 2007; 39: 305-318. PMid:17558857 http://dx.doi.org/10.1080/00313020701329914

[35] D. Yao, C. Dai, S. Peng. Mechanism of the mesenchymal-epithelial transition and its relationship with metastatic tumor formation. Mol. Cancer Res. 2011; 9: 1608-1620. PMid:21840933 http://dx.doi.org/10.1158/1541-7786.MCR-10-0568

[36] B. Annamalai, X. Liu, U. Gopal, J. S. Isaacs. Hsp90 is an essential regulator of EphA2 receptor stability and signaling: implications for cancer cell migration and metastasis. Mol. Cancer Res. 2009; 7: 1021-1032. PMid:19567782 http://dx.doi.org/10.1158/1541-7786.MCR-08-0582

[37] H. Miao, D.-Q. Li, A. Mukherjee, H. Guo, A. Petty, J. Cutter et al. EphA2 mediates ligand-dependent inhibition and ligand-independent promotion of cell migration and invasion via a reciprocal regulatory loop with Akt. Cancer Cell. 2009; 16: 9-20. PMid:19573808 http://dx.doi.org/10.1016/j.ccr.2009.04.009

[38] A. B. Larsen, M. T. Stockhausen, H. S. Poulsen. Cell adhesion and EGFR activation regulate EphA2 expression in cancer. Cell Signal. 2010; 22: 636-644. PMid:19948216 http://dx.doi.org/10.1016/j.cellsig.2009.11.018

[39] N. Hiramoto-Yamaki, S. Takeuchi, S. Ueda, K. Harada, S. Fujimoto, M. Negishi et al. Ephexin4 and EphA2 mediate cell migration through a RhoG-dependent mechanism. J. Cell Biol. 2010; 190: 461-477. PMid:20679435 http://dx.doi.org/10.1083/jcb.201005141

[40] N. Zhou, W.-D. Zhao, D.-X. Liu, Y. Liang, W.-G. Fang, B. Li et al. Inactivation of EphA2 promotes tight junction formation and impairs angiogenesis in brain endothelial cells. Microvasc. Res. 2011; 82: 113-121. PMid:21726568 http://dx.doi.org/10.1016/j.mvr.2011.06.005

[41] B. Wang. Cancer cells exploit the Eph-ephrin system to promote invasion and metastasis: tales of unwitting partners. Sci Signal. 2011; 4: pe28. PMid:21632467 http://dx.doi.org/10.1126/scisignal.2002153

[42] D. Y. C. Heng, W. Xie, M. M. Regan, M. A. Warren, A. R. Golshayan, C. Sahi et al. Prognostic factors for overall survival in patients with metastatic renal cell carcinoma treated with vascular endothelial growth factor-targeted agents: results from a large, multicenter study. J. Clin. Oncol. 2009; 27: 5794-5799. PMid:19826129 http://dx.doi.org/10.1200/JCO.2008.21.4809

[43] B. Escudier, T. Eisen, C. Porta, J. J. Patard, V. Khoo, F. Algaba et al. Renal cell carcinoma: ESMO Clinical Practice Guidelines for diagnosis, treatment and follow-up. Annals of Oncology. 2012; 23: vii65. PMid:22997456 http://dx.doi.org/10.1093/annonc/mds227 